\title{
FRACTURE OF THE TIBIAL COMPONENT IN TOTAL KNEE ARTHROPLASTY: REPORT ON TWO CASES
}

Idemar Monteiro da Palma ${ }^{1}$, Rodrigo Pires e Albuquerque ${ }^{2}$, João Maurício Barretto ${ }^{3}$

\section{ABSTRACT}

The authors report the rare occurrence of two cases of fracture of the tibial component in total knee arthroplasty. They review the literature and discuss the main factors that can cause failure of the implants.

Keywords - Arthroplasty, Replacement, Knee. Postoperative Complications. Review.

\section{INTRODUCTION}

Total knee arthroplasty is a high-complexity procedure that is constantly evolving. It is basically indicated for patients with a diagnosis of knee osteoarthrosis or rheumatic diseases. Implants with more modern designs are made to resemble the anatomy of normal knees as much as possible. They are inserted using instruments that are increasingly precise, with less aggression to soft tissues, thus making surgical indications ever more wide-ranging.

The good results obtained from total knee arthroplasty (TKA) have been well documented in the literature, both with regard to pain relief and with regard to maintenance of these results over long-term follow-up ${ }^{(1-6)}$.

There are several complications inherent to this type of surgical procedure. Fractures in implants are a rare occurrence and are mostly seen in the literature in the form of case reports.

The aim of this study was to present two cases of fracture of the tibial component using the same model and type of prosthesis.

\section{Case 1}

The patient was a 68 -year-old woman with body mass index $>30$, who presented osteoarthrosis and underwent total knee arthroplasty on the left knee in January 2000, at the Orthopedics and Traumatology Service, Miguel Couto Municipal Hospital. The PCA prosthesis model was used (Howmedica ${ }^{\circledR}$ ). The patient underwent successive revisions with the physician responsible for this, but the varus angular deformity and range of motion remained unchanged after the initial postoperative period. In October 2008, the patient returned to her physician with worsening of the painful condition, and she was then referred to the knee outpatient clinic. Imaging examinations and laboratory tests were requested in order to assess the knee for possible TKA revision.

In January 2009, she went to the knee outpatient clinic for the first time with a condition of intense pain without any history of trauma and with laboratory tests that were negative for infection. In the physical examination, we observed varus knee deformity and a range of motion from 0 to $75^{\circ}$. In a radiographic examination on the knee while bearing weight, we observed a

1 - Orthopedist in the Knee Group, National Institute of Traumatology and Orthopedics, Rio de Janeiro, RJ, Brazil.

2 - Coordinator of the Knee Surgery Sector, Miguel Couto Municipal Hospital, Rio de Janeiro, RJ, Brazil.

3 - Former President of the Brazilian Society of Knee Surgery and Head of the Orthopedics Service, Santa Casa, Rio de Janeiro, RJ, Brazil.

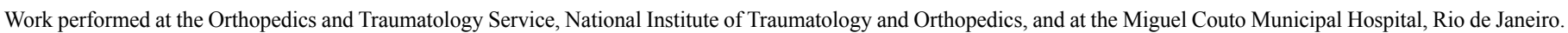
Correspondence: Av. Henrique Dodsworth, 83/105, Copacabana - 22061-030 - Rio de Janeiro, RJ. E-mail: rodalbuquerque@ibest.com.br

Work received for publication: April 22, 2010; accepted for publication: July 7, 2010. 
fracture in the tibial component (Figure 1). TKA revision surgery was indicated, and this was performed in August 2009 (Figures 2 and 3). During the immediate postoperative period, we observed pain relief and functional improvement of the knee.

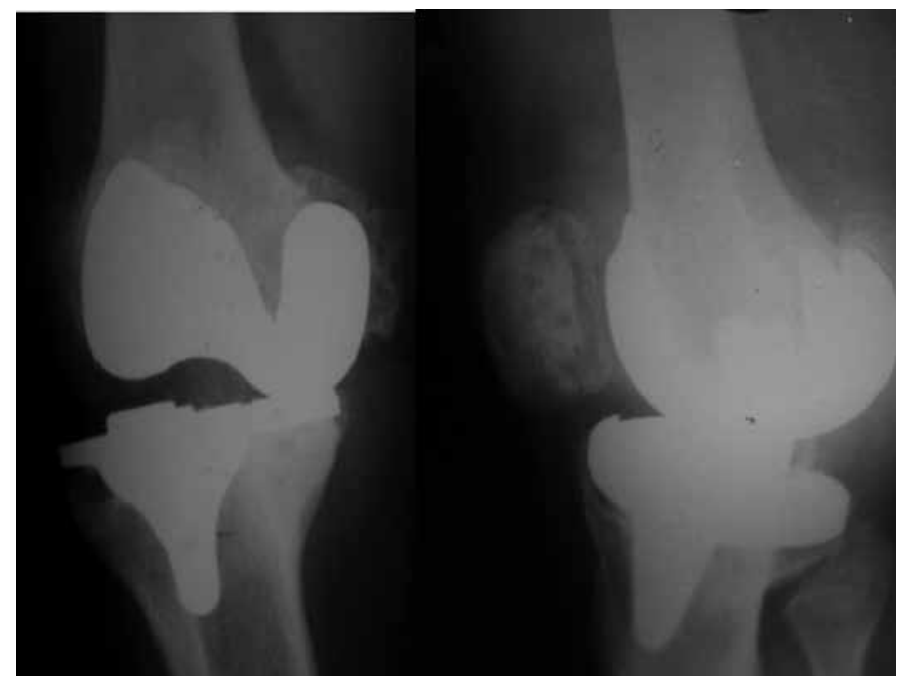

Figure 1- Preoperative radiograph of case 1.

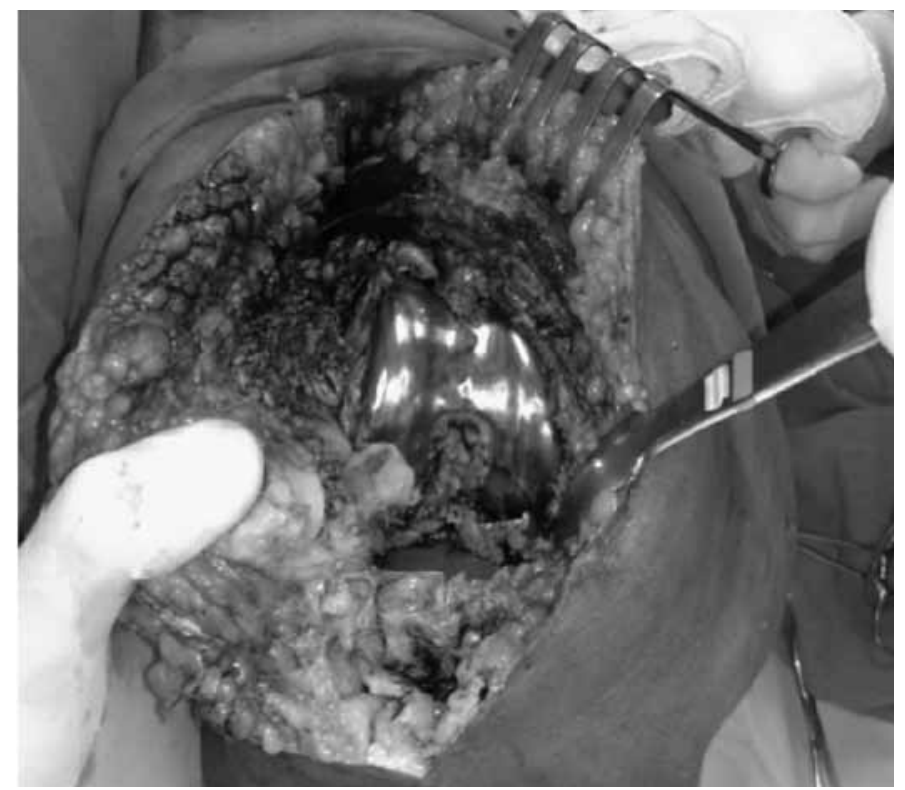

Figure 2 - Intraoperative view of case 1.

\section{Case 2}

The patient was a 72-year-old man with normal body mass index, who presented osteoarthrosis and underwent total arthroplasty on the left knee in January 1994, at a private hospital in the state of Rio de Janeiro. The PCA prosthesis model was used (Howmedica ${ }^{\circledR}$ ). The patient underwent successive revisions with the physician responsible for this, but

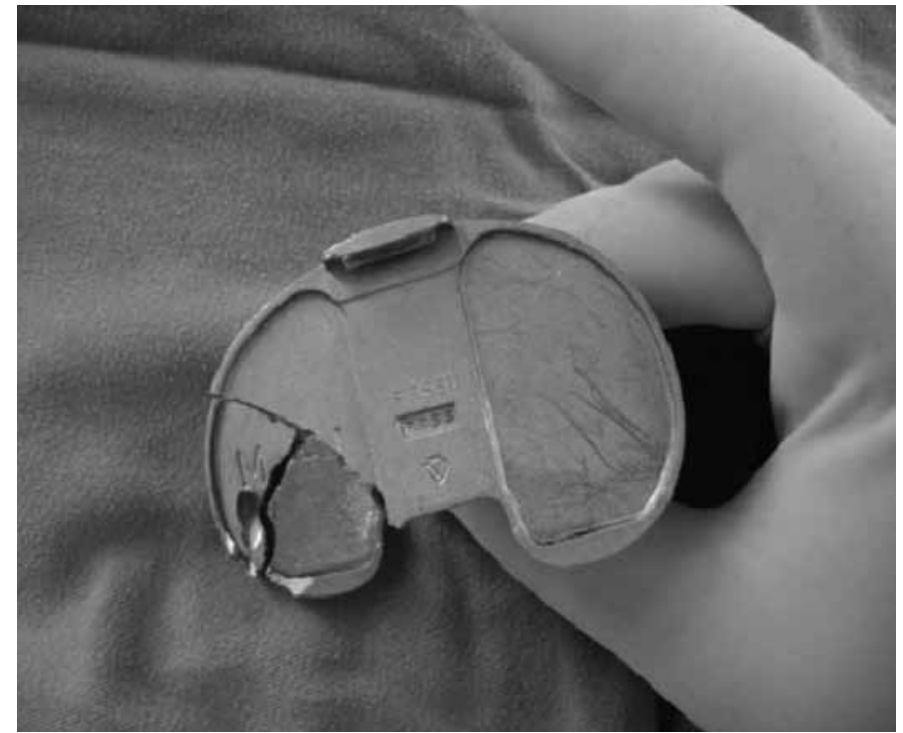

Figure 3- Fracture of the tibial component of case 1.

the varus angular deformity and range of motion remained unchanged. In May 1997, he returned to his physician with persistence of the painful condition, and he was then referred to the National Institute of Traumatology and Orthopedics. Imaging examinations and laboratory tests were requested in order to assess the knee for possible TKA revision. After screening, the patient entered the waiting list for TKA revision.

In April 1999, he went to the knee outpatient clinic of the National Institute of Traumatology and Orthopedics with a condition of intense pain, without any history or trauma and with laboratory tests that were negative for infection. In the physical examination and in the radiographic examination while bearing weight, we observed a varus knee deformity and a range of motion from 0 to $80^{\circ}$ (Figure 4 ). TKA revision surgery was indicated, and this was performed in June 1999 (Figures 5 and 6). During the immediate postoperative period, we observed pain relief and functional improvement of the knee.

\section{DISCUSSION}

Several factors may be involved in fractures of TKA implants. In the literature, the ones cited are: bone loss, misalignment, obesity, high activity level, manufacturing error and inappropriate design. Our opinion is that we agree with the above cited affirmation. Moreover, we believe that success in the surgical procedure depends on very many factors: the surgeon's familiarity with the procedure, good 

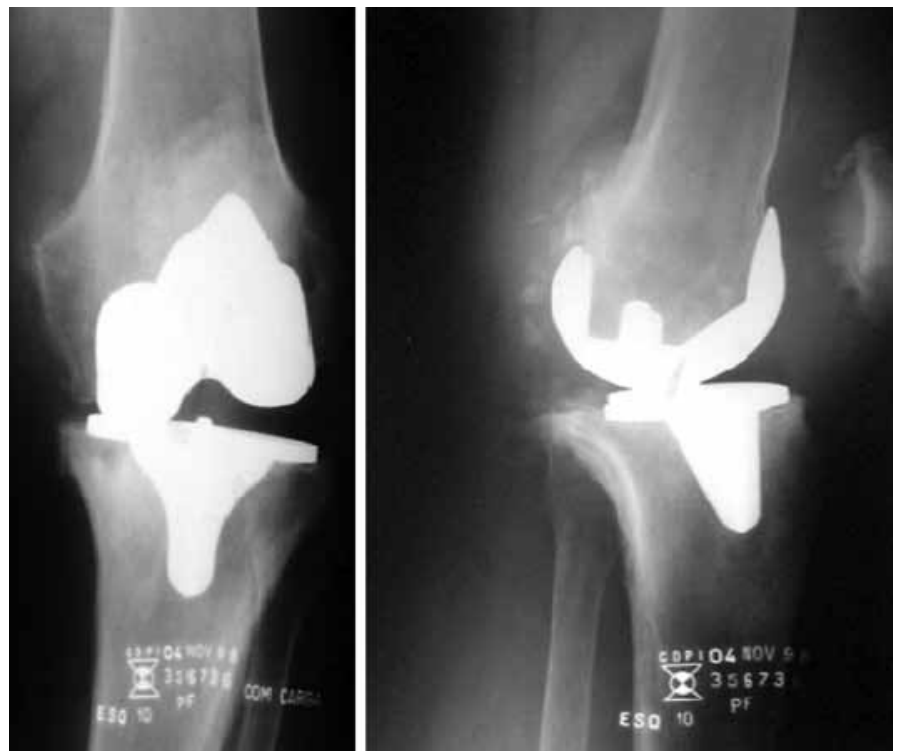

Figure 4 - Preoperative radiograph of case 2.

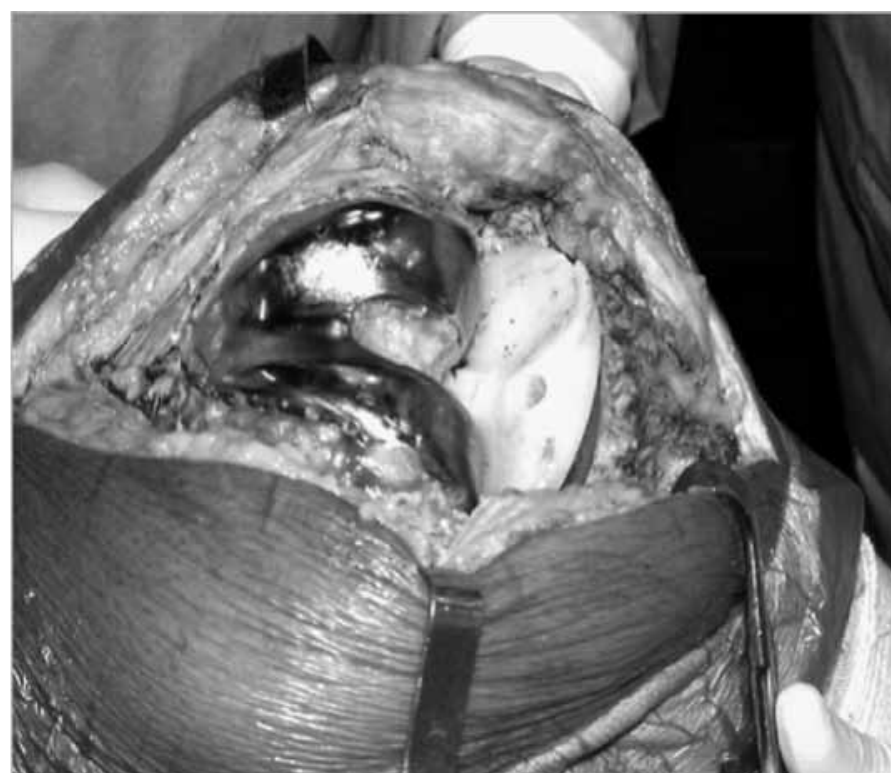

Figure 5 - Intraoperative view of case 2.

ligament balance, appropriate precision instruments and a good-quality durable implant.

In our view, the two implants in our sample remained in varus knee positioning because of inadequate ligament balance. Because of this, greater weight was borne on the medial compartment of the knee, thus facilitating fracturing of the implant. Luring et $\mathrm{al}^{(7)}$ corroborated our thinking and reported that misalignment of the implant creates osteolysis and generates cyclic overload on the prosthesis used. Swarts et $\mathrm{al}^{(8)}$ considered that correct alignment was the main factor in TKA success. Rousseau et $\mathrm{al}^{(9)}$ observed that early failure in TKA (excluding cases of infection) was re-

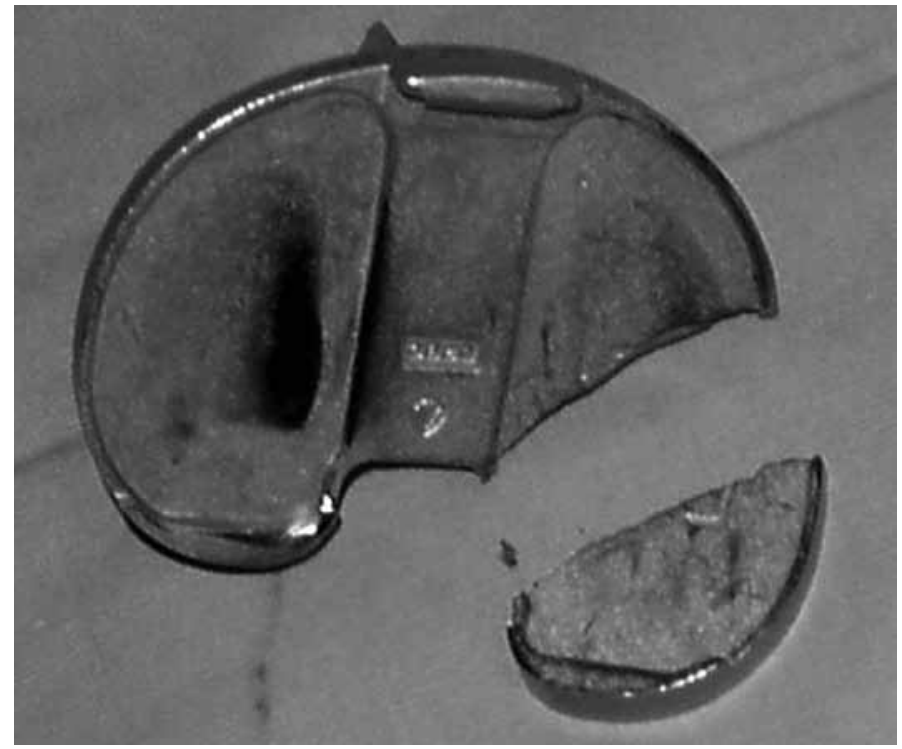

Figure 6 - Fracturing of the tibial component in case 2 .

lated to technical problems in prosthesis implantation that could be avoided.

The two implants used in our study were of the same model made in the United States (Howmedica ${ }^{\circledR}$ ). Flivik et $\mathrm{al}^{(10)}$ and Maruyama et $\mathrm{al}^{(11)}$ concluded from their studies that inappropriate design was the main factor involved in fracturing of the tibial component. In our study, the prosthesis used was of modern design, and what drew our attention was the similar fracture location in the two implants.

Wada et $\mathrm{al}^{(12)}$ observed that the thickness of femoral implants used was less than that of other types of prosthesis, and that this was a predisposing factor for the risk of fracture. In addition, they reported that their patients were not overweight, and they considered that their failure rate of $3.3 \%$ was high. In our opinion, the thickness of the implant is a fundamental factor for the durability of the TKA. When we correlated this with our series, we found that overweight associated with misalignment due to ligament imbalance was the determining factor in the fracturing of the implant seen in case 1 . It is generally known that obesity leads to greater wear on implants, and if this is associated with poor positioning of the prosthesis due to inadequate balance of soft tissues, the survival of the implant will be further diminished. Scott et $\mathrm{al}^{(13)}$ corroborated our thinking and added that asymmetrical forces in the knee following TKA could cause fracturing due to implant fatigue, implant failure or deformation of the plastic component. 
Whiteside et $\mathrm{al}^{(14)}$ found 32 cases of fracturing of the femoral component when the Ortholoc II model was used. They concluded that the design of this prosthesis predisposed towards occurrences of fractures because of the existence of a thinner area between the chamfer and the distal surface of the implant. For this reason, we advocate that biomechanical tests and better quality control should be performed when putting implants on the market. Cook et $\mathrm{al}^{(15)}$ and Mendes et $\mathrm{al}^{(16)}$ observed manufacturing errors that led to fracturing of implants. Morrey et $\mathrm{al}^{(17)}$ stated that the temperature used in manufacturing the prosthesis and irregularity in the porous surface were the main risk factors when we made correlations with implant manufacturing errors.

Huang et $\mathrm{al}^{(18)}$ and Han et $\mathrm{al}^{(19)}$ warned that after performing TKA, the wear on the polyethylene and occurrences of osteolysis should be observed. Early surgical intervention minimizes the risk of bone loss, and serious complications like loosening of the prosthesis, supracondylar fracture of the femur or implant fracturing can be avoided ${ }^{(18)}$.

Abernethy et $\mathrm{al}^{(20)}$ observed that fracturing of the tibial component was the main cause of early revision in TKA cases. After making a review of the literature, we do not agree with this affirmation. In our view, fracturing of the implant following TKA is a rare complication. We emphasize that TKA consists of soft-tissue surgery, in which ligament balance is the starting point for adequate positioning of the implant and survival of the prosthesis. The failure in our cases was due to inadequate ligament balance, which generated asymmetrical forces and breakage of the implants.

\section{REFERENCES}

1. Font-Rodriguez DE, Scuderi GR, Insall JN. Survivorship of cemented total knee arthroplasty. Clin Orthop Relat Res. 1997;(345):79-86.

2. Ritter MA. The Anatomical Graduated Component total knee replacement: a long-term evaluation with 20-year survival analysis. J Bone Joint Surg Br. 2009;91(6):745-9.

3. Ritter MA, Herbst SA, Keating EM, Faris PM, Meding JB. Long-term survival analysis of a posterior cruciate-retaining total condylar total knee arthroplasty. Clin Orthop Relat Res. 1994;(309):136-45.

4. Rand JA, Ilstrup DM. Survivorship analysis of total knee arthroplasty. Cumulative rates of survival of 9200 total knee arthroplasties. J Bone Joint Surg Am. 1991;73(3):397-409.

5. Insall JN, Kelly M. The total condylar prosthesis. Clin Orthop Relat Res. 1986;(205):43-8.

6. Gandhi R, Tsvetkov D, Davey JR, Mahomed NN. Survival and clinical function of cemented and uncemented prostheses in total knee replacement: a metaanalysis. J Bone Joint Surg Br. 2009;91(7):889-95.

7. Luring C, Perlick L, Schubert T, Tingart M. A rare cause for knee pain: fracture of the femoral component after TKR. A case report. Knee Surg Sports Traumatol Arthrosc. 2007;15(6):756-7.

8. Swarts E, Miller SJ, Keogh CV, Lim G, Beaver RJ. Fractured Whiteside Ortholoc II knee components. J Arthroplasty. 2001;16(7):927-34.

9. Rousseau MA, Lazennec JY, Catonné Y. Early mechanical failure in total knee arthroplasty. Int Orthop. 2008;32(1):53-6.

10. Flivik G, Ljung P, Rydholm U. Fracture of the tibial tray of the PCA knee. A case report of early failure caused by improper design. Acta Orthop Scand. 1990;61(1):26-8.
11. Maruyama M, Terayama K, Sunohara H, Adachi T, Suzuki S, Fukuzawa T. Fracture of the tibial tray following PCA knee replacement. A report of two cases. Arch Orthop Trauma Surg. 1994;113(6):330-3.

12. Wada M, Imura S, Bo A, Baba H, Miyazaki T. Stress fracture of the femoral component in total knee replacement: a report of 3 cases. Int Orthop. 1997;21(1):54-5.

13. Scott RD, Ewald FC, Walker PS. Fracture of the metallic tibial tray following total knee replacement. Report of two cases. J Bone Joint Surg Am. 1984;66(5):780-2.

14. Whiteside LA, Fosco DR, Brooks JG Jr. Fracture of the femoral component in cementless total knee arthroplasty. Clin Orthop Relat Res. 1993;(286):71-7.

15. Cook SD, Thomas KA. Fatigue failure of noncemented porous-coated implants. A retrieval study. J Bone Joint Surg Br. 1991;73(1):20-4.

16. Mendes DG, Brandon D, Galor L, Roffman M. Breakage of the metal tray in total knee replacement. Orthopedics. 1984;7:860-2.

17. Morrey BF, Chao EY. Fracture of the porous-coated metal tray of a biologically fixed knee prosthesis. Report of a case. Clin Orthop Relat Res. 1988;(228):182-9.

18. Huang $\mathrm{CH}$, Yang $\mathrm{CY}$, Cheng $\mathrm{CK}$. Fracture of the femoral component associated with polyethylene wear and osteolysis after total knee arthroplasty. J Arthroplasty. 1999;14(3):375-9.

19. Han CD, Han CW, Yang IH. Femoral component fracture due to osteolysis after cemented mobile-bearing total knee arthroplasty. J Arthroplasty. 2009;24(2):323.e7-12.

20. Abernethy PJ, Robinson CM, Fowler RM. Fracture of the metal tibial tray after Kinematic total knee replacement. A common cause of early aseptic failure. J Boné Joint Surg Br. 1996;78(2):220-5. 